\title{
HOW CAN WE MAKE CITY? PARTICIPATORY STRATEGIES
}

\author{
J.A. Herrera Martín ${ }^{1}$, M.V. de Montes Delgado² \\ ${ }^{1}$ Department of Architectural Construction II, University of Seville (SPAIN) \\ ${ }^{2}$ Department of Architectural Construction II, University of Seville (SPAIN)
}

\begin{abstract}
The question How can we make city? initiates the pedagogical process of the teaching innovation carried out in the subject Urban Development Management and Control of the third academic year of the Grade of Building Engineering of the University of Seville.

This teaching innovation aims to transform the traditional teaching model into a new one based on participatory strategies. The innovation was carried out during the academic year 2014-2015. From two improvement cycles, it is possible to establish guidelines to apply lessons learned in the development of the teaching of future academic years.

The first improvement cycle is focused on the instrumental knowledge of town planning and its real application in Andalusian municipalities. On the other hand, the second improvement cycle comprehends analysis and practical implementation of the knowledge and skills acquired, by means of the study of a piece of news connected with town planning.

The experience developed starts from the analysis of previous teaching activity and subject contents. The first step consists of answering questions such as: what is the essential of the subject?; what is the complementary of the subject?; how is the subject structured?; what relations are indispensable to give sense to the essential contents identified?; how do we build relations between contents?; how can we organize the sequence of contents?; how do we learn?; what steps are required to acquire an autonomous, deep and collaborative knowledge?
\end{abstract}

All preceding questions invite us to reflect on our teaching experience. Furthermore, in our teaching innovation activities, these questions are taken as the initial element of the development of the pedagogical process.

Hence, sessions developed in class are based on asking questions and the learning process is supported by the development and presentation of projects.

The activities carried out in class pursue the following goals: the reconnassaince of the elements that define the city; the establishment of connections between urban landscape, city and town planning instruments; the identification of urban areas; and, finally, the search of a better understanding of the urban reality through town planning instruments.

The learning process methodology begins with the formulation of a global question, that has to be able to provoke in the students curiosity and interest for its solution and for the search of answers. This initial question is permanently present and sets a reference for different approaches of the problem solution that may arise in class.

Therefore, contents are developed through questions. These questions are connected with specific projects, so that students can learn specific concepts in the context of a concrete reality.

The construction of a suitable working environment in class becomes essential to foster collaborative work; thus students can ask themselves questions, share doubts, advances and progress with their peers.

The global questions asked should be able to be divided in smaller queries, facilitating their study and analysis by parts. The importance of the drawing of diagrams and sketches is also highlighted in the teaching innovation experience.

In summary, the teaching innovation activities proposed are focused on the implementation of alternative teaching methods from the traditional ones in order to allow students to learn in an autonomous, deep and collaborative way.]

Keywords: City, town planning instrument, teaching innovation, questions, teaching-learning process. 


\section{CONTEXT OF THE INNOVATION}

Teaching innovation activities presented are developed in the subject of Urban Development Management and Control, which is located in the third academic year of the Grade of Building Engineering of the University of Seville, during the first semester of 2014-2015 academic year, with the main objective of improving the learning processes involved.

A peculiarity of the participating students profile is that they have previous technical qualifications as far as they belong to a special group of adaptation from the former Degree of Technical Architecture to the present Grade of Building Engineering. The subject Urban Development Management and Control is a new and compulsory subject of this later degree and means their first contact with town planning.

The class group is divided into teams. As a result, there are seven teams of 3-4 people each in class.

The classroom is equipped with a blackboard, low-height drawing tables and mobile chairs, which allows changes in the arrangement of furniture to introduce new ways of working and interacting. It is also suitable as far as technology services are concerned: audiovisual media, cannon projector, computer, Internet connection and plugs to supply power to laptops are provided.

\section{TEACHING PRINCIPLES}

The contents of this teaching innovation experience are based on the following teaching principles:

- They must be chosen by taking into consideration their actual and immediate applicability by students.

- The presentation of contents must be connected with students familiar knowledge to help their understanding, comprehension and application; these contents must be linked with questions and structured in a hierarchical and clear way [1].

- Contents must be organized in an comprehensible map, in which connections between elements are highlighted. These contents must be open, allowing students to deepen in their study and to establish connections with other contents of the same or different disciplines.

The methodology implemented in the innovation model proposed incorporates the teaching principles listed below:

- Learning process starts with a global question that allows different approaches and answers. The objective of this beginning is to foster curiosity and interest among students in the question solution and search of posible answers.

- This initial global question must be present in every moment, as it is the reference with which contrast the different approaches to the problem solution proposed [2].

- Questions must be placed in a particular and specific project, allowing students to develop their own learning process in the context of a concrete reality and specific concepts.

- Questions proposed must be able to be divided into other questions and analysed by parts to facilitate their study; the use of diagrams and outlines allows to contextualize the analysis in its proper place and moment at any time.

- It is essential to create a suitable atmosphere in class in which students can work in a collaborative way, asking themselves questions and sharing doubts, advances and progress with their peers.

The sequence of activities starts with a question, later the study and debate of this question and its subquestions is developed in an individual and collective way. Subsequently, a map of possible answers to these questions is outlined. These answers proposed are assessed in a critical way and reorganized. This process of approach to an agreed answer ends by drawing some final conclusions [3].

As far as the teaching assessment is concerned, the following teaching principles are considered: 
- The verification of the initial level of knowledge of the students is required to adapt the learning process to the class situation. For that purpose, open questions to get to know the previous level of knowledge and skills of the students in relation with the subject contents, concepts and discipline are asked.

- Throughout the learning process is necessary to check that the concepts applied by students are suitable, coherent and properly integrated and organized [4].

- Periodically, the way in which students acquire, connect and integrate new concepts with former ones must be verified by asking them questions and testing them; tests used must contain sequences of open questions, which have possible alternative answers that can be exposed in the way of diagrams and conceptual maps.

For the assessment of the performance of the students the skills listed below must be considered:

- Participation and involvement in class, especially in the solution of the problems set out.

- Proactive and collaborative attitude in the individual work and in the team one.

- Synthesis capacity and ability to connect concepts and procedures.

- Arguing skills, which involve the way in which students expose and argue their answers, ideas and projects.

- The level of correlation between the conclusions drawn by students and the procedures used to get to them.

Also the assessment of the teacher performance is required in order to be able to improve the learning process. This assessment is carried out by anonymous questionnaires that collect the information needed.

\section{GENERAL CONTENT MAP}

The subject is organized in two improvement cycles in which global questions are asked at their beginning as a resource to allow the learning process to get developed. The first half of the semester is focused on the study of the general principles and concepts of urban development. In the following figures (Fig. 1) (Fig. 2), the contents developed in this first improvement cycle and the global questions asked are shown [5].
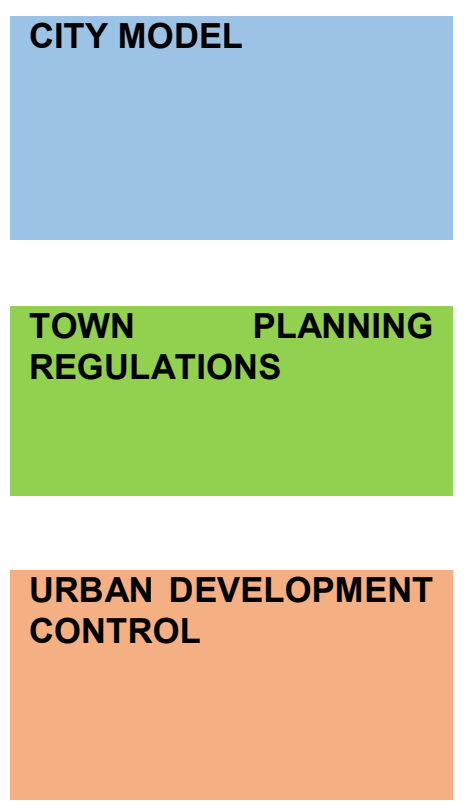

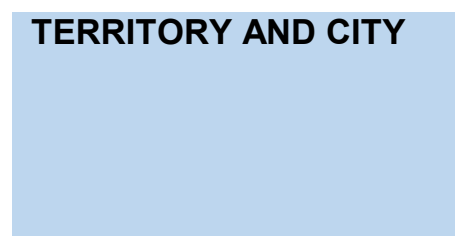

TOWN PLANNING
INSTRUMENTS

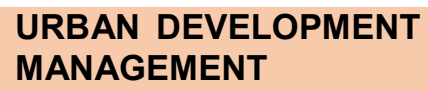

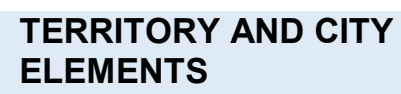

CONTENT OF TOWN

PLANNING INSTRUMENTS

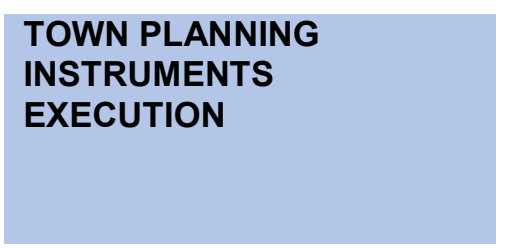

Fig. 1 Content map of the first improvement cycle I (Source: Own elaboration) 


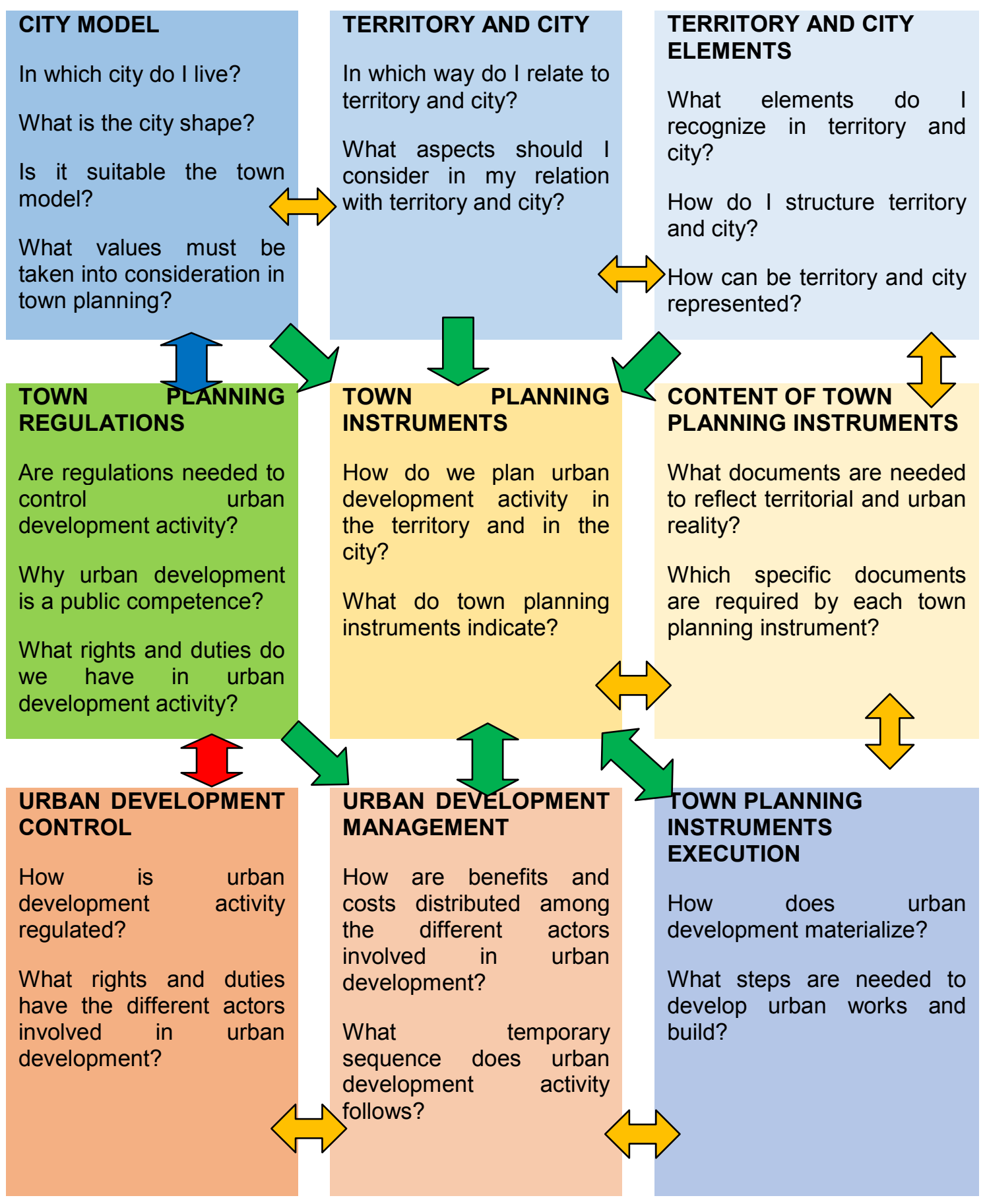

Fig. 2 Content map of the first improvement cycle II (Source: Own elaboration)

On the other hand, in the second half of the semester, after having learnt the general principles and concepts of urban development shown above, a case study (Fig. 3 ) is analysed in order to understand how they can be applied in actual situations. This case study is collected from a piece of news.

\section{URBAN DEVELOPMENT CASE STUDY}

$\begin{array}{llll}\text { MANAGEMENT } & \text { What? } & \text { Soil, Building, Heritage } & \text { Public } \\ & \text { Who? } & \text { Actors, Civil Service } & \text { Private } \\ \text { EXECUTION } & \text { When? } & \text { Urban development schedule } & \text { Participation }\end{array}$




$\begin{array}{clll}\text { CONTROL } & \begin{array}{l}\text { How? } \\ \text { With what? } \\ \text { Why? }\end{array} & \begin{array}{l}\text { Town planning instruments } \\ \text { Regulations } \\ \text { Sustainable development }\end{array} & \begin{array}{l}\text { Organization } \\ \text { Permissions } \\ \text { Disciplinary } \\ \text { measures }\end{array} \\ \text { Regulations } & \text { WITH WHAT APPROACH } & \\ & \text { Town Planning Instruments } & \text { References } & \\ & \text { CONCLUSIONS / IMPACT } & \\ & & \text { NEGATIVE } & \\ & & \end{array}$

Fig. 3 Content map of the second improvement cycle (Source: Own elaboration)

\section{METHODOLOGY AND SEQUENCE OF ACTIVITIES OF THE FIRST IMPROVEMENT CYCLE}

The methodology implemented is focused on problem-based activities, in which a sequence of questions is asked around a key concept or idea that it is wanted to be analysed. The learning process undergoes a cyclical revision of its development and results in order to allow its continuous improvement. The following figure (Fig. 4) represents this methodology, which starts with the formulation of a problem (PB) in the form of a question, continues with the analyses of theorical (T) and practical (P) approaches and ends with a solution of the problem in the form of a theoretical concept or idea. Finally, the learning process undergoes the necessary feedback to allow its future improvement.

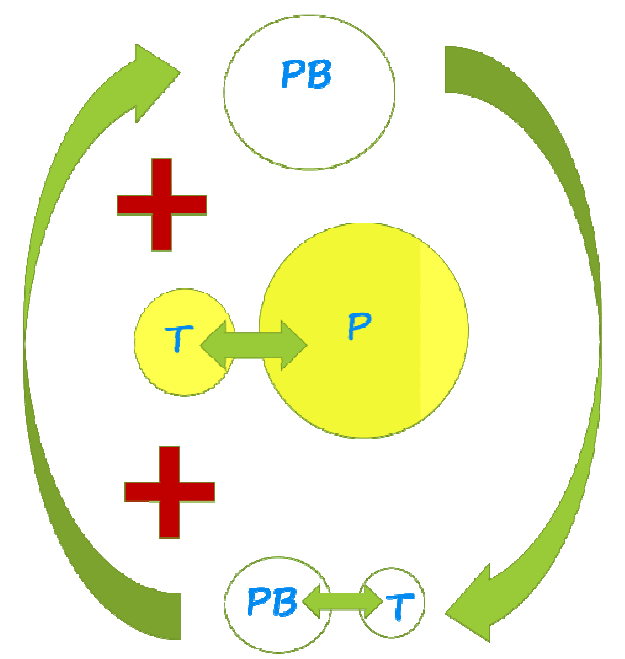

Fig. 4 Methodology of the first improvement cycle (Source: Own elaboration)

On the other hand, the sequence of activities can be divided in different tasks. These tasks are listed below and shown in Fig. 5: 


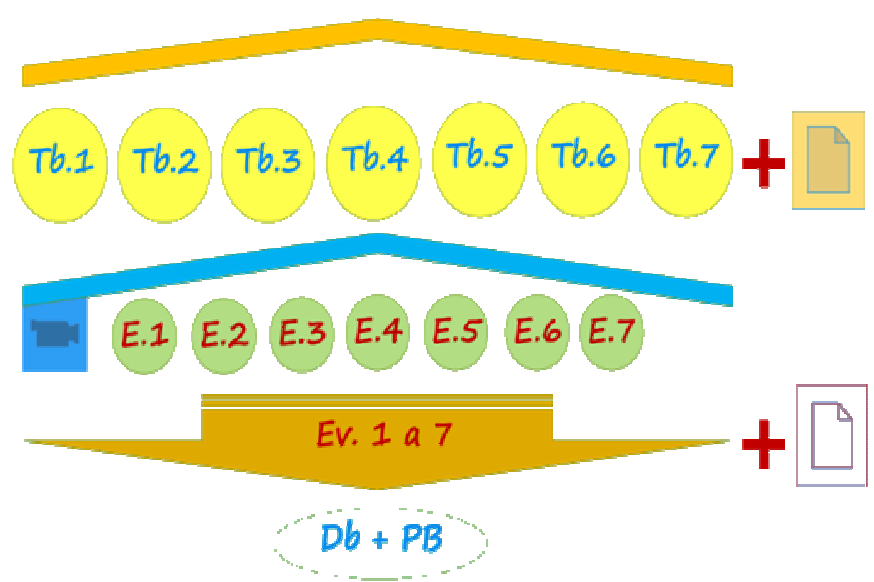

Fig. 5 Sequence of activities of the first improvement cycle (Source: Own elaboration)

[PB] Introduction and explanation of the problem needed to be solved. It consists in the study, analysis and presentation of a current town planning instrument of an Andalusian municipality.

[Tb.n] Team work under teacher coaching. The seven teams formed work in class the topic proposed counting on the teacher for support at any moment.

[E.n] Work presentation. After handing in the study carried out, each team has to present in class the work developed by using a PowerPoint presentation of three minutes long.

[Ev.] Collective assessment of the presentations exposed in class. Each team assesses the seven presentations exposed, included their own one in an exercise of self-assessment. For this purpose, each team is given a questionnaire.

$[\mathrm{Db}+\mathrm{PB}]$ Collective debate and assessment of the learning process and the results obtained in the innovation project carried out [6].

\section{METHODOLOGY AND SEQUENCE OF ACTIVITIES OF THE SECOND IMPROVEMENT CYCLE}

The methodology of the second improvement cycle starts by presenting a particular problem. This problem consists in analysing, presenting and debating a case study related to urban development issues, identified from a piece of news. This work allows students to understand how the general principles and concepts of urban development can be applied in real situations.

Therefore, the sequence of activities of this second improvement cycle is as follows:

- Introduction and explanation of the problem needed to be solved. It consists in the search, study, analysis and presentation of a current urban development issue, echoed in press. Students are given a questionnaire with simple questions that need to be answered in their analysis of the issue chosen, such as: what is the piece of news about?; who are involved?; when does it happen?; where does it happen?; how does it happen?; why does it happen?; what economic, social and environmental impacts have the issue under study?.

- Team search of news on the Internet under teacher coaching. The seven teams are the same as the ones formed in the first improvement cycle unless there is a dysfunction in any of them that needs to be overcome.

- Sharing of the news found in class and collective assessment of their interest and suitability to the activity proposed. 
- Analysis of the issue chosen by elaborating diagrams and conceptual maps and by answering the questionnaire given.

- Sharing of the analysis developed by each team in class. Identification of aspects of interest that need to be studied in depth.

- Writing of the final report in $\mathrm{A} 3$ format. This report comprehends the analysis of the most important aspects of the urban development issue chosen, such as its scope and its economic, social and environmental impact.

- Handing in the final report.

- Collective debate and assessment of the learning process and the results obtained in the innovation project carried out.

\section{DESCRIPTION OF THE FIRST IMPROVEMENT CYCLE}

The session starts by projecting a PowerPoint presentation with the initial global question of the course. The question chosen is: How do we make city? Students are told to solve this question by analysing a current town planning instrument of an Andalusian municipality, as the University of Seville, where the innovation is being carried out, is placed in this Spanish region. This analysis must be collected in the form of a PowerPoint presentation that will be exposed in class in the order and duration given. They are also told that they will have to assess the performance of the presentations exposed and of the learning process developed.

Before the work is carried out, the initial level of knowledge about urban development management discipline of the students is measured by means of a questionnaire.

The 22 students of the adaption group are divided into seven teams to develop this work in a collaborative way. The average level of knowledge of the members of each work team is intended to be balanced. Each team counts on at any time with the advice and support of the teacher in class if doubts arise.

Team work develops without incidents and there is a free-flowing dialogue between teacher and students. As a result, the established day, every team hands in their analysis and presents it by using a PowerPoint presentation of three minutes long. This short period of time for the presentation tests students skill to synthesize the work the have been developing during weeks.

Presentations pass off successfully and proposed schedule is carried out. During the presentations, students pay attention and write down the aspects they consider of interest in order to be able to assess their performance.

For this final collective assessment, each team is given a pair of questionnaires:

- One questionnaire for the assessment of the presentations exposed, included their own presentation. It includes aspects such as the structure and content of the analysis, the references looked up, its presentation, the conclusions drawn and a global assessment of each team work.

- Other questionnaire for the assessment of the learning process and the results obtained in the innovation project carried out. This second questionnaire comprehends aspects such as the degree of interest in the study of town planning instruments, the degree of satisfaction with the methodology implemented, the most positive and negative aspects of the learning process and ideas for further improvement.

After handing in the assessment questionnaries, a collective debate is developed. This debate highlights the significant progress made by students in the knowledge of town planning instruments and how the methodology adopted fosters their interest and involvement in the learning process. 


\section{DESCRIPTION OF THE SECOND IMPROVEMENT CYCLE}

This second improvement cycle begins with an explanation of the activity proposed. It consists in the search, study, analysis and presentation of a current urban development issue, echoed in press. Students are given a questionnaire with simple questions that need to be answered in their analysis of the issue chosen, such as: what is the piece of news about?; who are involved?; when does it happen?; where does it happen?; how does it happen?; why does it happen?; what economic, social and environmental impacts have the issue under study?. Students are invited to modify and improve the analysis by adding questions that they consider significant or changing the questions proposed for their enhancement.

The seven class teams search of news on the Internet under teacher coaching. By debating in a brainstorming session with their peers and teacher the news found, they choose the most interesting and suitable one and get ideas of approaches for the research.

During the following sessions, each team elaborates different diagrams and conceptual maps to answer the proposed questions in order to choose the option that best synthesizes and connects their ideas in an $\mathrm{A} 3$ format.

The analysis of the piece of news chosen goes without incident in a good class atmosphere where all teams work in an intensive and concentrated way.

After handing in the final report and sharing the most significant aspects of the news studied in class, a collective debate and assessment of the learning process and the results obtained in the innovation project take place. For this purpose, each student is required to fulfil an assessment questionnaire previously. The debate is held in a participatory and orderly way.

A significant conclusion drawn is that collaborative work and sharing in class diagrams, conceptual maps and questionnaires contribute to enhance the analyses developed and to make students feel leading actors in the learning process. The general feeling is that the strategies implemented had lead to a successful and participatory development of the learning process.

As far as the teacher work is concerned, it is noticed that a specific assessment and monitoring of each work team requires more time than the available [7].

\section{ASSESSMENT OF THE LEARNING PROCESS}

Comparing the results of the different questionnaires fulfilled by students and the two practices presented, a significant progress in the level of knowledge of the urban development management discipline is realized.

The students of the adaptation group are technical architects that have come back to university to complete their tertiary education. In their former Degree of Technical Architecture, the study of urban development management was not included in the syllabus. Therefore, the average initial level of knowledge of the discipline is very low (69\%), except for a minority that have had professional experience in this field as is illustrated in Fig. 6.

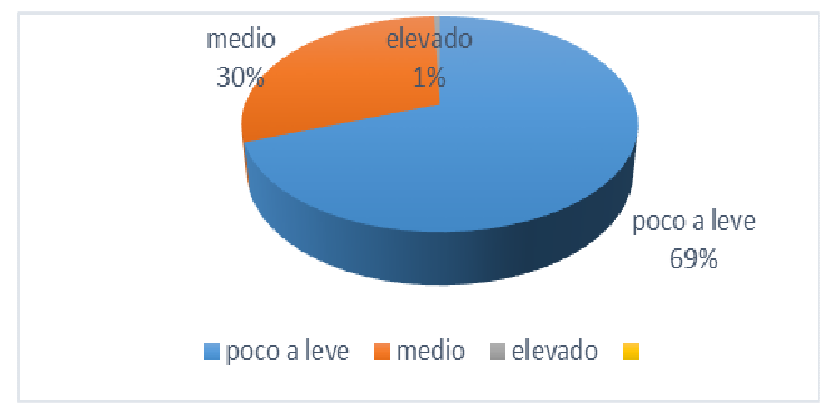

Fig. 6 Assessment of the students initial level of knowledge of the discipline (Source: Own elaboration) 
Moreover, the final level of competence of the students can be classified in three levels as can be shown in Fig. 7: medium-low (34\%), medium (57\%) and high (9\%).

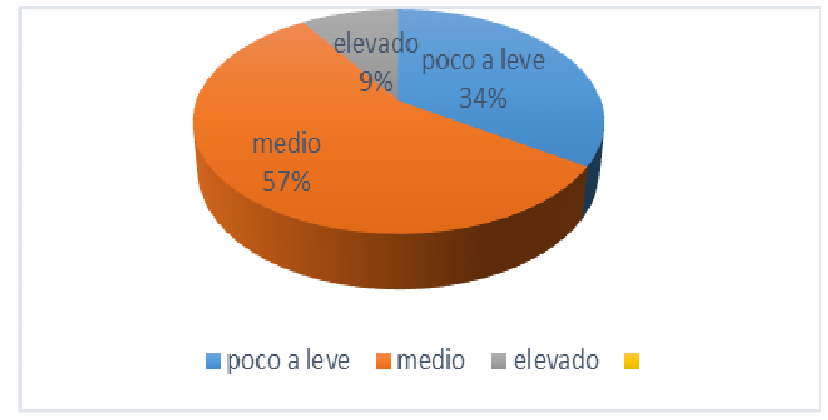

Fig. 7 Assessment of the students final level of knowledge of the discipline (Source: Own elaboration)

These results show that there is still much to improve to increase the average level of competence. The complexity of this discipline and the great universe of new concepts, besides the limited time available for its study and training, are revealed as important barriers for students to achieve a high level of specialization.

On the other hand, the interest and involvement of the students in the learning process have reached the excellence. The methodology adopted has proved to awake students interest in a totally new discipline for them and to foster their participation in the improvement cycles proposed. This interest will allow them to deepen in the knowledge of the discipline in the future and to pay continuous attention to the changes in regulations and practices that may come.

Additionaly, another significant conclusion drawn is that collaborative work and sharing in class diagrams, conceptual maps and questionnaires contribute to enhance the analyses developed and to make students feel leading actors in the learning process.

As far as the teacher work is concerned, a reflexive exercise of self-assessment is required. For this exercise two questions are posed:

- How does the teacher see himself during each improvement cycle?

- What are the problems observed?

The two teachers involved in this learning process have felt themselves as catalysts of the knowledge and skills transformation processes undergone in class.

In these transformation processes, the first problem identified by these two teachers is the limited time available to attend to every work team and to share in class all the contributions made by each.

Additionaly, the second problem is the different level of performance and progress of the different work teams that reveals the lack of balance in the profile of the students involved as far as knowledge and training in the discipline is concerned.

\section{CONCLUSIONS AND IMPROVEMENT PROPOSALS}

It can be stated that the innovation activity has taken place favourably as a significant improvement has been achieved in the learning process as show the results obtained from the different assessment questionnaires given to students and the self-assessment of the teachers involved.

Hence, some proposals are elaborated in order to mitigate the problems identified.

- The elaboration of guidelines to optimize and deepen work performance is considered beneficial. 
- Furthermore, the establishment of intermediate goals before ending each learning cycle will contribute to consolidate and increase their progress, such as short presentations of the progress of the work before the final presentation throughout the semester.

- Moreover, an exhaustive planning and scheduling of the sequence of activities must be shared with the students from the beginning and be constantly followed and updated.

- Intervention strategies to balance the initial level of knowledge of the urban development management discipline that students present are needed to be researched.

- Clear statement of the subject objectives and the ways to reach them successfully.

- Further clarification of the concepts that integrate the urban development management discipline, connecting them and with real practices.

On the other hand, the strengths identified in the methodology implemented will continue being fostered in future learning processes for their permanent improvement.

- As Ken Bain states students are the main actors of learning process, so it has to be designed starting from the consideration of their needs, interests and looking for commitments.

- Working in collaborative teams that motivate students to keep on learning in and outside class. It is also important to help them learn in an autonomous way too.

- The rigorous verification of the initial level of knowledge of the discipline and the expectations that students have is essential to adapt the learning process to their real needs.

- The use of questions to initiate the learning process and to awake students interest in researching possible solutions to the problem posed.

- Sharing in class diagrams, conceptual maps and questionnaires contribute to enhance the analyses developed and to make students feel leading actors in the learning process.

In summary, the innovation carried out has gone with a significant level of satisfaction among the actors involved. The results obtained open a wide field of future work and improvement in order to achieve the highest levels of competence and involvement that may be possible.

So, learning processes must be always understood as natural processes in which all parts collaborate in the progress of their own knowledge, fully convinced that with effort and illusion all objectives stateds are able to be reached and will be useful for their personal and professional, present and future, development [8].

\section{REFERENCES}

[1] Bain, K. (2007). What the Best College Teacher Do. The President and the Fellows of Harvard College, 2004. Lo que Hacen los Mejores Profesores Universitarios. Traductor. Barberá, O. Universitat de València Valencia. pp.49.

[2] Ibid., pp.68.

[3] McDonald, K.A.(1987) Science and Matematics Leaders Call for Radical Reform in Calculus Teaching. Chronicle of Higher Education, November 4, 1987. pp. 1.

[4] Ibid [1], pp.34.

[5] Solís Ramírez, E. et al. (2012) ¿Cómo representar el conocimiento curricular de los profesores de ciencias y su evolución?. Enseñanza de las Ciencias. Revista de Investigación y Experiencias. pp. 9-30.

[6] Piñeiro, $M^{a}$.R. et al. (1998) Enseñar y aprender el espacio geográfico. Nau Llibres pp. 5-28

[7] Porlan, R. (2000) El diario del profesor, un recurso para la investigación en el aula. pp.21-23

[8] Souto, X.M. (1994) Implicaciones didácticas del estudio geográfico de las ciudades. Investigaciones geográficas, pp. 93-118. 